Published in final edited form as:

J Gastrointest Surg. 2015 May ; 19(5): 917-926. doi:10.1007/s11605-015-2789-0.

\title{
PROMIS for Laparoscopy
}

Juliane Bingener, M.D.., Jeff A. Sloan, Ph.D. ${ }^{*} \dagger$, Drew K. Seisler ${ }^{\dagger}$, Andrea L. McConico*, Pam E. Skaran ${ }^{\star}$, David R. Farley, M.D. ${ }^{*}$, and Mark J. Truty, M.D. ${ }^{*}$

"Department of Surgery, Mayo Clinic, Rochester, MN

tDepartment of Health Sciences Research, Mayo Clinic, Rochester, MN

\begin{abstract}
Introduction-We tested the responsiveness of the National Institutes of Health-sponsored Patient-Reported Outcomes Measures Information System (PROMIS) global health short form and a linear analog self-assessment for laparoscopy.
\end{abstract}

Methods-From 5/2011 through 12/2013, patients undergoing laparoscopy responded to patient reported outcome questionnaires perioperatively. Composite and single item scores were compared.

Results-One hundred fifteen patients, mean age 55, 58\% female, were enrolled. Visual analog pain scores differed significantly from baseline (mean 1.7 \pm 2.3 ) to postoperative day 1 (mean 4.8 \pm 2.6 ) and 7 (mean 2.5 \pm 2.1 ) ( $\mathrm{p}<0.0001$ ). PROMIS physical subscale and total physical component subscore differed significantly from baseline $(14.4 \pm 3.0 / 47.4 \pm 8.3)$ to postoperative day $1(12.7 \pm 3.2 / 42.1 \pm 8.8)$ (p 0.0007/0.0003), due to everyday physical activities $(\mathrm{p}=0.0001)$. Linear analog self-assessment scores differed from baseline for pain frequency $(\mathrm{p}<0.0001)$, pain severity $(\mathrm{p}<0.0001)$ and social activity ( $\mathrm{p}=0.0052) ; 40 \%$ of subjects reported worsening in PROMIS physical T-score to postoperative day 1 and $25 \%$ to postoperative day 7 . Linear analog selfassessment mental well-being scores were worse in $32 \%$ of patients at postoperative day 7 , emotional well-being in $28 \%$, social activity in $24 \%$, and fatigue in $20 \%$ of patients.

Conclusion-Single items and change from baseline are responsive perioperative quality of life assessments for laparoscopy.

\section{Keywords}

Patient reported outcome; laparoscopy; pain; fatigue; quality of life; social activity

\section{INTRODUCTION}

Recent years have seen significant innovations in minimally invasive gastrointestinal surgery including natural orifice surgery, robotics, single-port laparoscopic surgery and endoluminal procedures. To assist surgeons and patients select appropriate procedures in

Corresponding Author: Juliane Bingener, M.D., Mayo Clinic, 200 First Street SW, Rochester, MN 55905, Ph: 507-284-2717, Fax: 507-284-5196, bingenercasey.juliane@ mayo.edu.

Presented as a poster at the $54^{\text {th }}$ Annual Meeting of the Society for Surgery of the Alimentary Tract, May 17-21, 2013, Orlando, FL. 
comparison with one another, morbidity and mortality have limited utility. The likelihood of an adverse event in the perioperative period is often low, thus detecting a morbidity difference between two surgical approaches in a randomized trial is not feasible. Similar constraints apply to length of hospital stay.

Attention has recently turned to patient-reported outcomes and a number of trials have included quality of life (QOL) instruments to compare minimally invasive surgical approaches.[1-11] In addition, patient-reported outcomes are gaining importance as components of value based purchasing and reimbursement strategies. We wanted to test the performance of two short global quality of life tools. First, we wanted to test a validated National Institutes of Health (NIH)-sponsored Patient-Reported Outcomes Measurement System (PROMIS) for use with minimally invasive surgical procedures.[12] The PROMIS tool bank is supported by the NIH and the Patient Centered Outcomes Research Institute (PCORI) for research proposals and has found acceptance with the Federal Drug Administration as outcome measure, thus understanding the outcomes expected with commonly performed laparoscopic procedures would provide a baseline for clinical and research projects. The PROMIS tool has resulted from large QOL research collaborations over the last decade, is now frequently used for cancer-related QOL research and is significantly shorter than the previously frequently used SF36. PROMIS is a publically funded and available tool and does not require payment to use. PROMIS does require weighted scoring however, which is supported by online tools (www.nihpromis.org/). In addition, we were interested in a previously validated single item, linear-analog selfassessment tool (LASA).[13] This tool is unique in that it can be used at the bedside similar to the visual analog scale (VAS), and single items can be used independently from the entire questionnaire. We wanted to evaluate which of the domains may be most affected by perioperative changes and therefore would provide an efficient way of capturing patientreported outcomes and possibly enable real-time interventions. Both instruments are 10 questions each and thus correspond to patients' preference for short QOL tools.

\section{METHODS}

From May 2011 through December 2013, consecutive patients undergoing basic and advanced laparoscopic procedures were enrolled for this Institutional Review Boardapproved study. Basic laparoscopic procedures consisted of procedures such as laparoscopic cholecystectomy or diagnostic laparoscopy with biopsy. Advanced laparoscopic procedures included splenectomy, adrenalectomy, and laparoscopic ventral or inguinal hernia repair. After consent was obtained, the patients completed the PROMIS global health short form (PROMIS 10), the LASA questionnaire and the $10 \mathrm{~cm}$ VAS for pain assessment. The PROMIS global short form is validated for 7-day recall and has been previously used for 24$\mathrm{hr}$ recall. The LASA tool has been validated for $24-\mathrm{hr}$ recall. The patients then underwent surgery and the pain scale was again obtained as the patient entered the recovery room. A repeat measurement of both the PROMIS and the LASA was obtained at 4 hours postoperatively, 1 day, and 7 days postoperatively. The patient's operative procedure and any conversion to open surgery were also noted. Study data were collected and managed using REDCap electronic data capture tools hosted at Mayo Clinic. REDCap (Research Electronic Data Capture) is a secure, web-based application designed to support data capture 
for research studies, providing 1) an intuitive interface for validated data entry; 2) audit trails for tracking data manipulation and export procedures; 3) automated export procedures for seamless data downloads to common statistical packages; and 4) procedures for importing data from external sources.[14 Each QOL tool was then scored and both composite and single item responses were compared over time using repeated measures analysis. Attention was paid to both the mean scores for the groups and their change over time, as well as the changes within the individuals. Changes within individuals attempt to answer the question: how many patients will feel better or worse after surgery and for how long?

A clinically meaningful change from baseline (better/worse) has previously been defined as equal or more than $1.5 \mathrm{~cm}$ change on the VAS, 0.1 in the EQ5D (standardized, non-disease specific European quality of life 5 dimensions score) or larger than 0.5 standard deviation change in the PROMIS T-scores (total physical or mental component subscores) or LASA score.[15-17] To allow comparisons with other studies, the EQ5D score was calculated from the PROMIS global scores as follows: $(\mathrm{EQ} 5 \mathrm{D}$ score $=0.19123+(0.00672 \times$ Global2 $)$ $+(0.00527 \times$ Global 3$)+(0.00830 \times$ Global 4$)+(0.04550 \times$ Global 6$)+(0.02713 \times$ Global7rescored $)+(0.01305 \times$ Global8rescored $)+(0.00613 \times$ Global9 $)+(0.02502 \times$ Global10rescored). QOL scores significantly below the population mean are described as QOL deficits, here defined as LASA overall QOL scores of $<5$ out of 10.

Scores were compared by age groups, gender and advanced or basic procedures using t-test and chi-square tests and repeated measures models as appropriate. Missing data were not included in the analysis. With 115 patients, mean estimates are accurate to within 19\% times the standard deviation of each QOL measure with $95 \%$ confidence.

\section{RESULTS}

One hundred fifteen patients with a mean age of $55( \pm 15)$ were enrolled in the study. Sixtyseven patients (58\%) were female; the mean body mass index was $31( \pm 7.4)$. Preoperatively, 112 patients returned their questionnaires. Of those, 59 patients underwent a basic laparoscopic procedure and 53 patients underwent an advanced procedure. Three patients were converted to an open procedure and were included in the analysis. At the postoperative time points, 96, 90, and 91 patients provided the scores for analysis. Eighteen patients (16\%), mean age 53 years old, $57 \%$ female, $70 \%$ undergoing basic laparoscopy, did not mail in any scores after they left the hospital.

\section{Group means}

At baseline the patients revealed mean physical and mental T-scores consistent with the 2001 United States census mean score (approximately 50, see Table 1). The mean preoperative VAS score was also as expected in patients presenting for an operation. For all patients, the mean pain VAS scale revealed statistically and clinically significant differences from baseline (mean 1.7 \pm 2.3 ) to postoperative day 1 (mean 4.8 \pm 2.6 ) and 7 (mean 2.5 \pm 2.1 ) $(\mathrm{p}<0.0001)$ (Figure 1). There was no statistically significant difference between VAS scores by age $(\mathrm{p}=0.08)$ or gender $(\mathrm{p}=0.46)$; however, patients undergoing cholecystectomy and other basic procedures reported lower pain scores $(\mathrm{p}=0.001)$ than patients undergoing advanced procedures. 
The PROMIS physical subscale, physical T-score and EQ5D revealed clinically and statistically significant differences from baseline $(14.4 \pm 3.0 / 47.4 \pm 8.3 / 0.7 \pm 0.01)$ to postoperative day $1(12.7 \pm 3.2 / 42.1 \pm 8.8 / 0.6 \pm 0.01)(\mathrm{p}=0.0004 / 0.0001 / 0.0008)$ (Figure 2), driven by answers to a question about everyday physical activities ( $\mathrm{p}=0.0001$ ) (Figure 3). The overall mean PROMIS mental T-score scores did not reveal clinically significant changes over time The group mean LASA scores revealed significant differences from baseline for overall QOL $(\mathrm{p}=0.036)$, social activity $(\mathrm{p}=0.0048)$, pain severity $(\mathrm{p}<0.0001)$ and pain frequency $(\mathrm{p}<0.0001)$. Figure 4 shows LASA pain frequency scores by procedure, suggesting that the advanced procedures may contribute to this finding. Unlike the PROMIS scores, LASA physical well-being did not reveal a significant difference from baseline; LASA fatigue revealed statistically significantly worse fatigue in the advanced procedure group, $\mathrm{p}=0.038$. (Figure 5)

Preoperatively, $17 \%$ of all patients presenting for a laparoscopic surgery exhibited a QOL deficit (Table 2). Figure 6 depicts how the proportion of patients with a QOL deficit changed over time, depending on the age group. Younger patients experienced larger fluctuations; the number of patients with a QOL deficit increased by $50 \%$ from baseline on day 1 and decreased by $50 \%$ from baseline by day 7 . The number of patients over 65 years old and with a QOL deficit also increased by $50 \%$ from baseline and remained at that level by day 7 .

When change from baseline within subject was assessed, $40 \%$ of subjects reported a clinically meaningful worsening in PROMIS physical-T score on postoperative day 1 , which persisted in $25 \%$ of patients to postoperative day 7 . In addition to LASA pain and fatigue, social activity scores were clinically worse in $24 \%$ of the patients at postoperative day 7 . Table 3 reports the percentage of patients feeling clinically significantly better or worse at the different time points as measured by LASA. Two-thirds of patients reported no meaningful change throughout the post-surgical period. Few patients were clinically better. LASA physical well-being was the most resistant to change. Anxiety did not change significantly from baseline ( $\mathrm{p}=0.185$ ). The overall quality of life was worse in $17 \%$ of patients at one week postoperatively. Table 4 provides a quick overview of item responsiveness which has been of interest in the literature. The overall well-being item of the PROMIS-10 identified a higher proportion of individuals with worsening scores than the LASA item. The physical well-being item of PROMIS had twice as many individuals with worsening scores compared to the LASA physical item. For mental well-being the comparison was reversed, showing the LASA identifying almost twice as many patients with worse outcome than PROMIS. The fatigue scores were similar for both LASA and PROMIS. Pain frequency is not assessed in the PROMIS-10.

\section{DISCUSSION}

Patient-centered outcome reporting is gaining importance for the comparison of minimally invasive procedures. A significant body of literature describes the use of QOL tools in cancer treatment including cancer surgery. [18-22] Pain is an outcome well known to the surgical patient and thus pain and the physical and social limitation resulting from it are of interest. 'Fatigue' has recently been of interest as a predictor of survival and may well be a 
surrogate for the speed of recovery.[23,24] There is a paucity of useful data in the minimally invasive surgical environment for benign disease.

A number of trials have included QOL instruments such as the SF 36 to compare minimally invasive surgical methods.[1-11] Many trials are not able to demonstrate any overall QOL differences between procedures when the outcomes are measured at one month postoperatively, limiting the utility of these QOL tools as presently administered and evaluated to compare effectiveness.

In this study we use two short QOL tools with frequent administration in a short time period. Our study detects significant changes from baseline that correspond to findings in the Visual Analog Pain Scale, one of the frequently used tools for the comparison of surgical procedures. Below we examine several reasons that may improve the utility of QOL tools for minimally invasive surgery: a shorter measurement interval, the inclusion of sub-scores in addition to total scores and the attention to within subject changes.

\section{a) Measurement interval}

A one-month follow-up is recommended when studying chronic disease and cancer treatment. This time interval may be too long for a minimally invasive surgical procedure. It appears that for the minimally invasive surgical approaches, many of the changes in QOL have returned close to baseline after seven to fourteen days. For example, the Clinical Outcomes of Surgical Therapy (COST) Trial[25] revealed that the QOL scores differed at two weeks between the laparoscopic and open colectomy patients; after two months however, no differences were noted.[26,27] Therefore, reporting timeframes of one or three months may not capture acute changes in QOL, especially when comparing minimally invasive procedures to each other. Our study delineates the most significant patient impairment relative to pain and QOL within the initial 24 to $48 \mathrm{hrs}$ postoperatively with group means returning close to baseline at day 7 . As in other studies, the longer the time interval, the higher the 'missingness' of data. In our study, $16 \%$ of patients did not return questionnaires after they left the hospital, despite multiple attempts to contact them and preaddressed envelopes being repeatedly supplied. The patients who did not return the questionnaires were slightly younger (53 vs 55 years) and had more basic procedures performed compared to the overall group ( $70 \%$ basic procedures versus $51 \%$ ). This population is likely younger and healthier than the overall population, however the missingness of data may have influenced our results. Thus, it is important to consider short intervals to decrease the missingness of data so that the results represent the population as closely as possible.

\section{b) Subscores}

Overall QOL encompasses physical, mental, social and spiritual domains. A minimally invasive surgical procedure may not impact all domains enough to have a clinically meaningful impact on the overall mean scores of an entire patient group. The subscores most affected by the intervention can demonstrate meaningful changes. In our study, the PROMIS physical T-score was more responsive in detecting the impact of the surgical procedure than the overall PROMIS T-score (= physical + mental T-score) for the entire group of patients. 


\section{c) Within subject changes}

Efficace et al suggested that the reporting of QOL data should include within subject changes to address the question how many patients felt better or worse.[28,29] Measurement of patients with worsening QOL one week postoperatively and patients with a QOL deficit can identify patients in need of more intense follow up. Our study reveals that one day after surgery one in three patients is clinically worse than before surgery in items like fatigue and pain. At one week after surgery, one in five patients is clinically better and one-half to twothirds do not experience a significant change in their well-being. We also noted a change in the proportion of patients with clinically meaningful QOL deficits and how that may be affected by demographic factors.

In summary, the subscores and the within subject changes appear to be the most sensitive parameters to detect the impact of minimally invasive surgery on patient well-being. Even when the overall group-mean did not show a statistically significant difference from baseline QOL score throughout the recovery period, about $30 \%$ of patients felt clinically meaningfully worse. The results from this study can be used in discussions with patients relative to their expectations of postoperative recovery. Further studies should elucidate which $30 \%$ of patients suffer more from a given surgical procedure and if targeted interventions can assist with their recovery. In our future studies we may limit questionnaires to pain scores, PROMIS physical T-score, LASA fatigue and social activity scores, which likely will be welcomed by patients and will reduce the analytic workload while delivering results.

As a whole, the surgical community should consider using validated short generic tools over a shorter postoperative time period and include within subject changes in the reporting as it adds to the overall group comparisons.

\section{Acknowledgments}

Funding: Research reported in this manuscript was supported by the National Institute of Diabetes and Digestive and Kidney Diseases of the National Institutes of Health under award number K23DK93553 and the National Cancer Institute CA154537-01 A1-03 and UL1 TR000135. The content is solely the responsibility of the authors and does not necessarily represent the official views of the National Institutes of Health or the National Cancer Institute.

\section{REFERENCES}

1. Horstmann R, Hellwig M, Classen C, Rottgermann S, Palmes D. Impact of polypropylene amount on functional outcome an dquality of life after inguinal hernia repair by the TAPP procedure using pure, mixed, and titanium-coated meshes. World J Surg. 2006; 30:1742-1749. [PubMed: 16902744]

2. Gholghesaei M, Langeveld HR, Veldkamp R, Bonjer HJ. Costs and quality of life after endoscopic repair of inguinal hernia versus open tension-free repair: A review. Surg Endosc. 2005; 19:816-821. [PubMed: 15880287]

3. Barkun JS, Wexler MJ, Hinchey EJ, Thibeault D, Meakins JL. Laparoscopic versus open inguinal herniorrhaphy: preliminary results of a randomized controlled trial. Surgery. 1995; 118(4):703-709. discussion 709-710. [PubMed: 7570325]

4. Snyder CW, Graham LA, Vick CC, Gray SH, Finan KR, Hawn MT. Patient satisfaction, chronic pain, and quality of life after elective incisional hernia repair: effects of recurrence and repair technique. Hernia. 2011; 15(2):123-129. [PubMed: 21072550] 
5. Langeveld HR, van't Riet M, Weidema WF, Stassen LP, Steyerberg EW, Lange J, Bonjer HJ, Jeekel J. Total extraperitoneal inguinal hernia repair compared with Lichtenstein (the LEVEL-Trial): a randomized controlled trial. Ann Surg. 2010; 251(5):819-824. [PubMed: 20395851]

6. Lirici MM, Califano AD, Angelini P, Corcione F. Laparo-endoscopic single site cholecystectomy versus standard laparoscopic cholecystectomy: results of a pilot randomized trial. Am J Surg. 2011; 202(1):45-52. [PubMed: 21600559]

7. Phillips MS, Marks JM, Roberts K, Tacchino R, Onders R, DeNoto G, Rivas H, Islam A, Soper N, Gecelter G, Rubach E, Paraskeva P, Shah S. Intermediate results of a prospective randomized controlled trial of traditional four-port laparoscopic cholecystectomy versus single-incision laparoscopic cholecystectomy. Surg Endosc. 2012; 26(5):1296-1303. [PubMed: 22083331]

8. Marks J, Tacchino R, Roberts K, Onders R, Denoto G, Paraskeva P, Rivas H, Soper N, Rosemurgy A, Shah S. Prospective randomized controlled trial of traditional laparoscopic cholecystectomy versus single-incision laparoscopic cholecystectomy: report of preliminary data. Am J Surg. 2011; 201(3):369-372. discussion 372-363. [PubMed: 21367381]

9. Ma J, Cassera MA, Spaun GO, Hammill CW, Hansen PD, Aliabadi-Wahle S. Randomized controlled trial comparing single-port laparoscopic cholecystectomy and four-port laparoscopic cholecystectomy. Ann Surg. 2011; 254(1):22-27. [PubMed: 21494123]

10. Bucher P, Pugin F, Buchs NC, Ostermann S, Morel P. Randomized clinical trial of laparoendoscopic single-site versus conventional laparoscopic cholecystectomy. Br J Surg. 2011; 98(12):1695-1702. [PubMed: 21964736]

11. Leung D, Denham W, Salabat M, Butt Z, Barrera E, Ujiki M. Single-incision laparoscopic cholecystectomy results in similar short-term postoperative pain and quality of life scores when compared to multi-incision: A prospective randomized blinded comparison. Surigcal Endsocopy and Other Interventional Techniques. 2011; 25(S239)

12. Garcia SF, Cella D, Clauser SB, Flynn KE, Lad T, Lai JS, Reeve BB, Smith AW, Stone AA, Weinfurt K. Standardizing patient-reported outcomes assessment in cancer clinical trials: a patientreported outcomes measurement information system initiative. J Clin Oncol. 2007; 25(32):51065112. [PubMed: 17991929]

13. Locke DE, Decker PA, Sloan JA, Brown PD, Malec JF, Clark MM, Rummans TA, Ballman KV, Schaefer PL, Buckner JC. Validation of single-item linear analog scale assessment of quality of life in neuro-oncology patients. J Pain Symptom Manage. 2007; 34(6):628-638. [PubMed: 17703910]

14. Harris PA, Taylor R, Thielke R, Payne J, Gonzalez N, Conde JG. Research electronic data capture (REDCap) - A metadata-driven methodology and workflow process for providing translational research informatics support. J Biomed Inform. 2009 Apr; 42(2):377-81. [PubMed: 18929686]

15. Norman GR, Sloan JA, Wyrwich KW. Interpretation of changes in health-related quality of life: the remarkable universality of half a standard deviation. Med Care. 2003; 41(5):582-592. [PubMed: 12719681]

16. Norman GR, Sloan JA, Wyrwich KW. The truly remarkable universality of half a standard deviation: confirmation through another look. Expert Rev Pharmacoecon Outcomes Res. 2004; 4(5):581-585. [PubMed: 19807551]

17. Sloan JA, Symonds T, Vargar-Chanes D, Friedly B. Practical guidelines for assessing the clinical significance of health-related quality of life changes within clinical trials. Drug Inf J. 2003; 37:2331.

18. Neben-Wittich MA, Atherton PJ, Schwartz DJ, Sloan JA, Griffin PC, Deming RL, Anders JC, Loprinzi CL, Burger KN, Martenson JA. Comparison of provider-assessed and patient-reported outcome measures of acute skin toxicity during a phase III trial of mometasone cream versus placebo during breast radiotherapy: The North Central Cancer Treatment Group (N06C4). Int J Radiat Oncol Biol Phys. 2010:397-402. [PubMed: 20888137]

19. Arndt V, Merx H, Stegmaier C, Ziegler H, Brenner H. Quality of life in patients with colorectal cancer 1 year After diagnosis compared with the general population: A population-based study. $\mathrm{J}$ Clin Oncol. 2004; 22(23):4829-4836. [PubMed: 15570086]

20. Sloan JA, Zhao X, Novotny PJ, Wampfler J, Garces Y, Clark MM, Yang P. Relationship between deficits in overall quality of life and non-small-cell lung cancer survival. J Clin Oncol. 2012; 30(13):1498-1504. [PubMed: 22454418] 
21. Velanovich $\mathrm{V}$. The association of quality-of-life measures with malignancy and survival in patients with pancreatic pathology. Pancreas. 2011; 40(7):1063-1069. [PubMed: 21785386]

22. Lee V, Cheng H, Li G, Saif MW. Quality of life in patients with pancreatic cancer. Journal of the Pancras. 2012; 13(2):182-184.

23. Schnadig ID, Fromme EK, Loprinzi CL, Sloan JA, Mori M, Li H, Beer TM. Patient-physician disagreement regarding performance status is associated with worse survivorship in patients with advanced cancer. Cancer. 2008; 113(8):2205-2214. [PubMed: 18780322]

24. Qi Y, Schild SE, Mandrekar SJ, Tan AD, Krook JE, Rowland KM, Garces YI, Soori GS, Adjei AA, Sloan JA. Pretreatment quality of life is an independent prognostic factor for overall survival in patients with advanced stage non-small cell lung cancer. J Thorac Oncol. 2009; 4(9):10751082. [PubMed: 19546817]

25. Nelson H, Sargent D, Wieand HS. Group fCOoSTCS. A comparison of laparoscopically assisted and open colectomy for colon cancer. N Engl J Med. 2004; 350:2050-2059. [PubMed: 15141043]

26. Stucky CC, Pockaj BA, Novotny PJ, Sloan JA, Sargent DJ, O'Connell MJ, Beart RW, Skibber JM, Nelson H, Weeks JC. Long-term follow-up and individual item analysis of quality of life assessments related to laparoscopic-assisted colectomy in the COST trial 93-46-53 (INT 0146). Ann Surg Oncol. 2011; 18(9):2422-2431. [PubMed: 21452066]

27. Weeks JC, Nelson H, Gelber S, Sargent D, Schroeder G. Short-term quality-of-life outcomes following laparoscopic-assisted colectomy vs open colectomy for colon cancer: a randomized trial. JAMA. 2002; 287(3):321-328. [PubMed: 11790211]

28. Efficace F, Bottomley A, Osoba D, Gotay C, Flechtner H, D'Haese S, Zurlo A. Beyond the development of health-related quality-of-life (HRQOL) measures: a checklist for evaluating HRQOL outcomes in cancer clinical trials--does HRQOL evaluation in prostate cancer research inform clinical decision making? J Clin Oncol. 2003; 21:3502-3511. [PubMed: 12972527]

29. Joly F, Vardy J, Pintilie M, Tannock IF. Quality of life and/or symptom control in randomized clinical trials for patients with advanced cancer. Ann Oncol. 2007; 18:1935-1942. [PubMed: 17698837] 


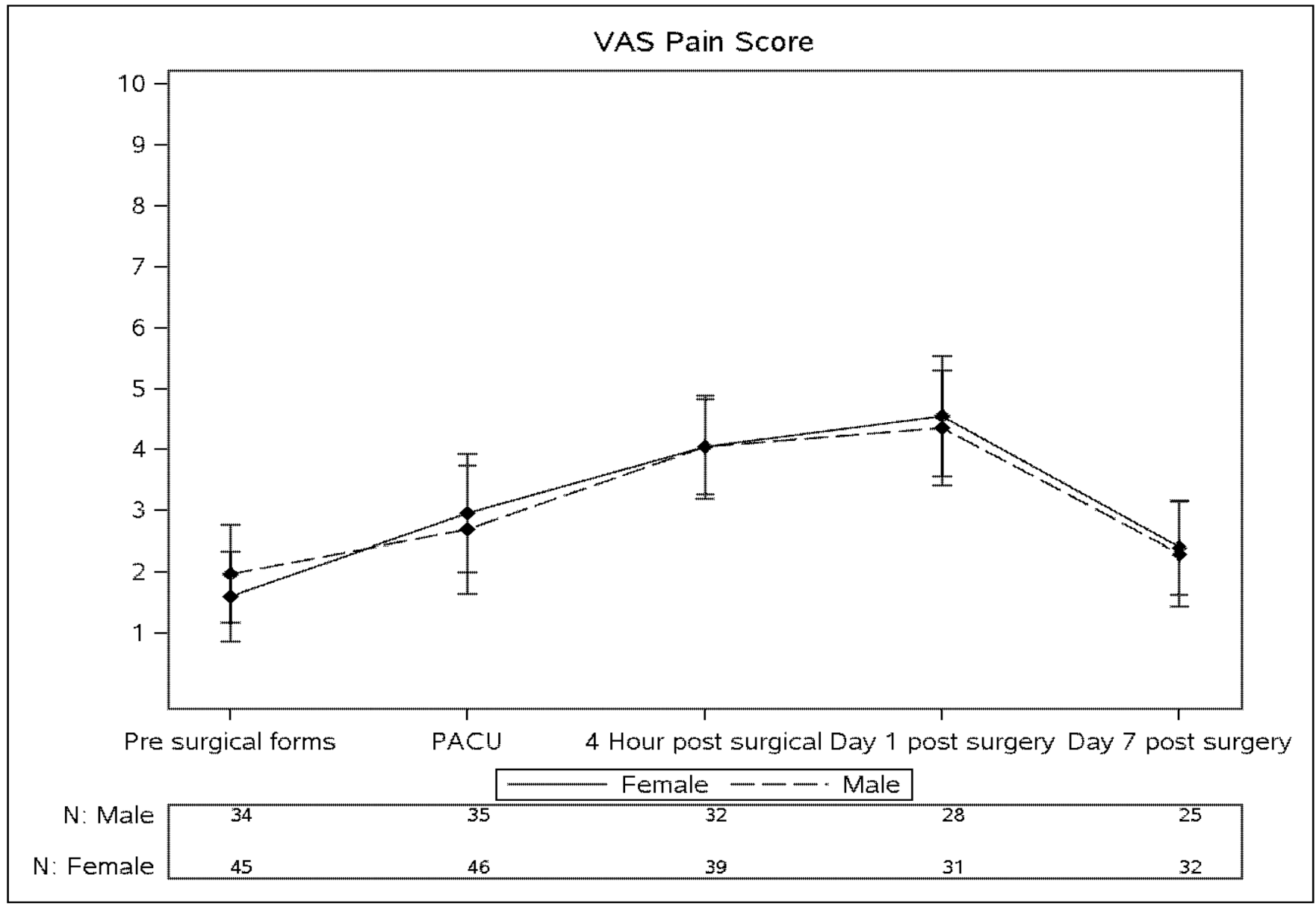

Figure 1.

VAS pain score over time, depicted by gender. $\mathrm{N}$ denotes the number of available data points from men and women included at each time point in the analysis. 
a

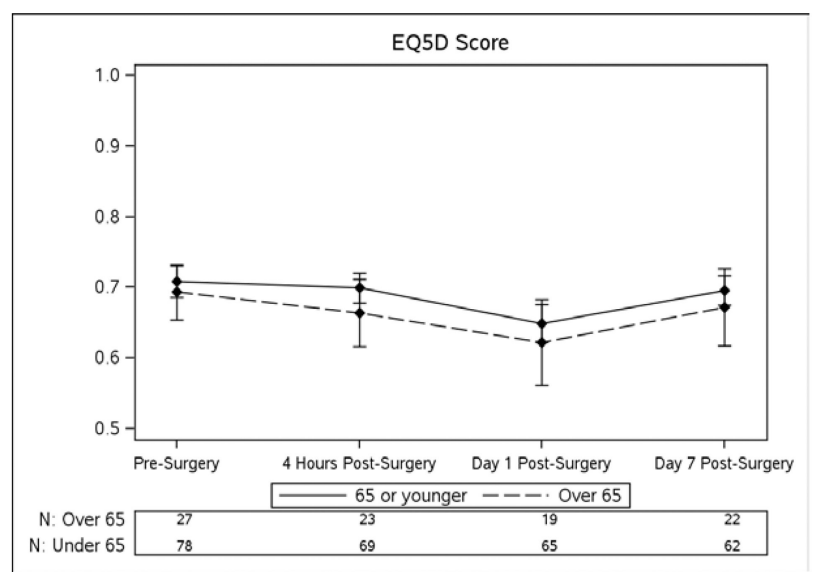

b
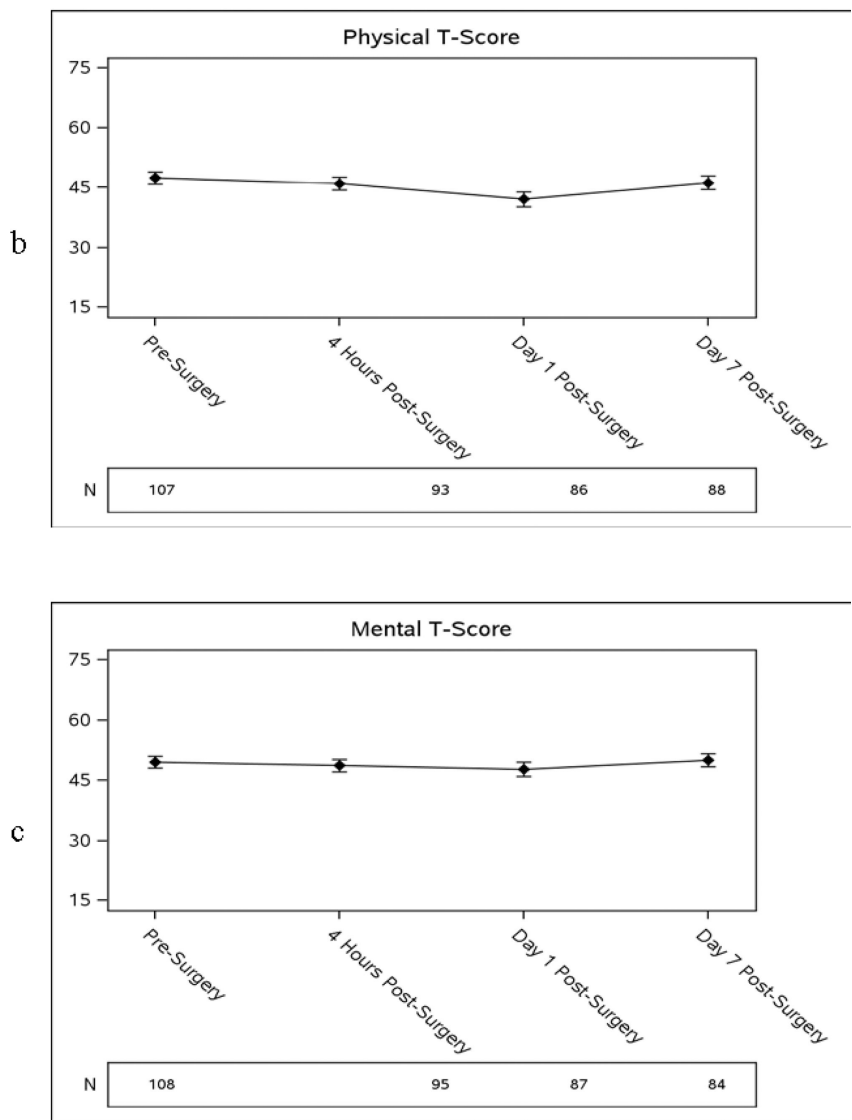

Figure 2.

a) EQ5D score by age over time. $\mathrm{N}$ denotes the number of available data points from patients older or younger than 65 included at each time point in the analysis b) PROMIS physical and c) PROMIS mental T-score for the entire study population over time. N denotes the number of available data points from the overall group included at each time point in the analysis 


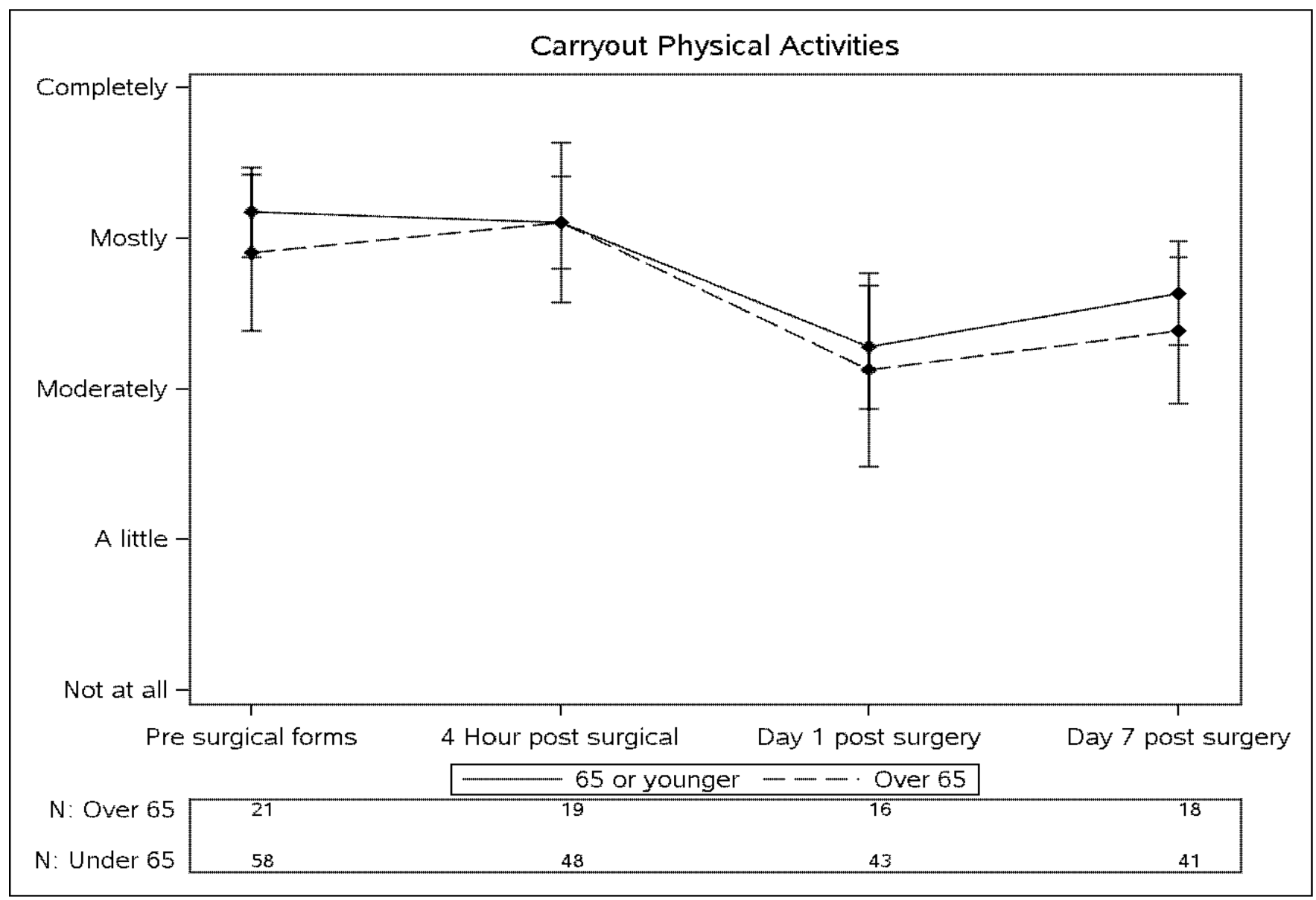

Figure 3.

Physical activity (PROMIS item) over time, depicted by age group. $\mathrm{N}$ denotes the number of available data points from patients older or younger than 65 included at each time point in the analysis 


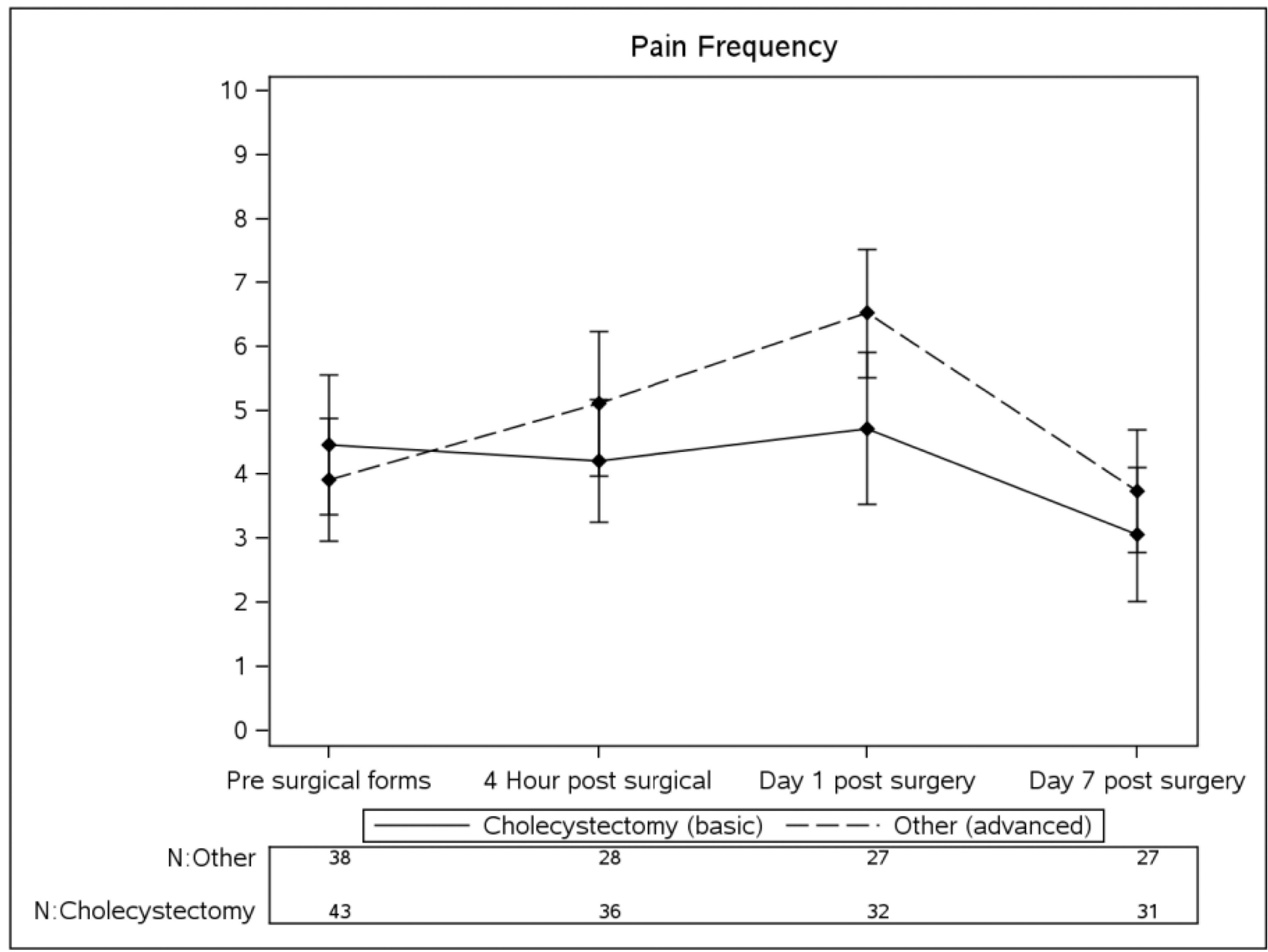

Figure 4.

LASA pain frequency scores by basic and advanced procedure over time. $\mathrm{N}$ denotes the number of available data points from patients undergoing basic or advanced laparoscopic procedures included at each time point in the analysis 
a

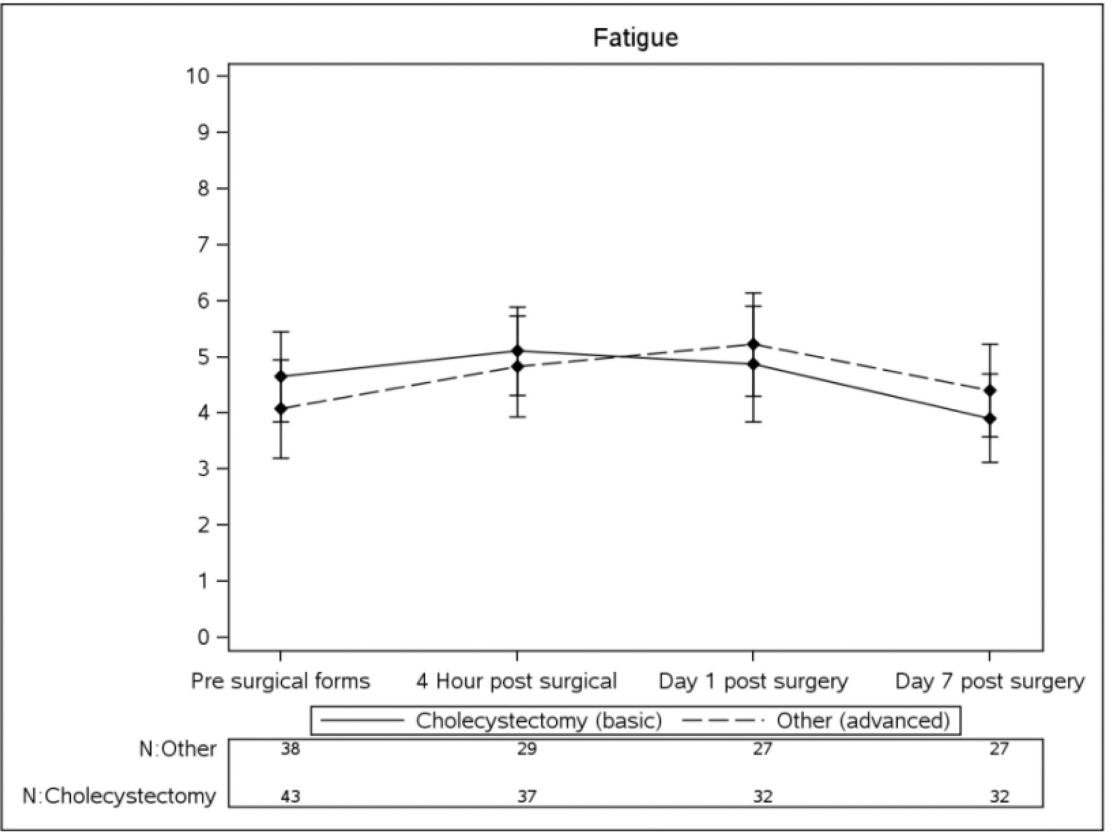

b

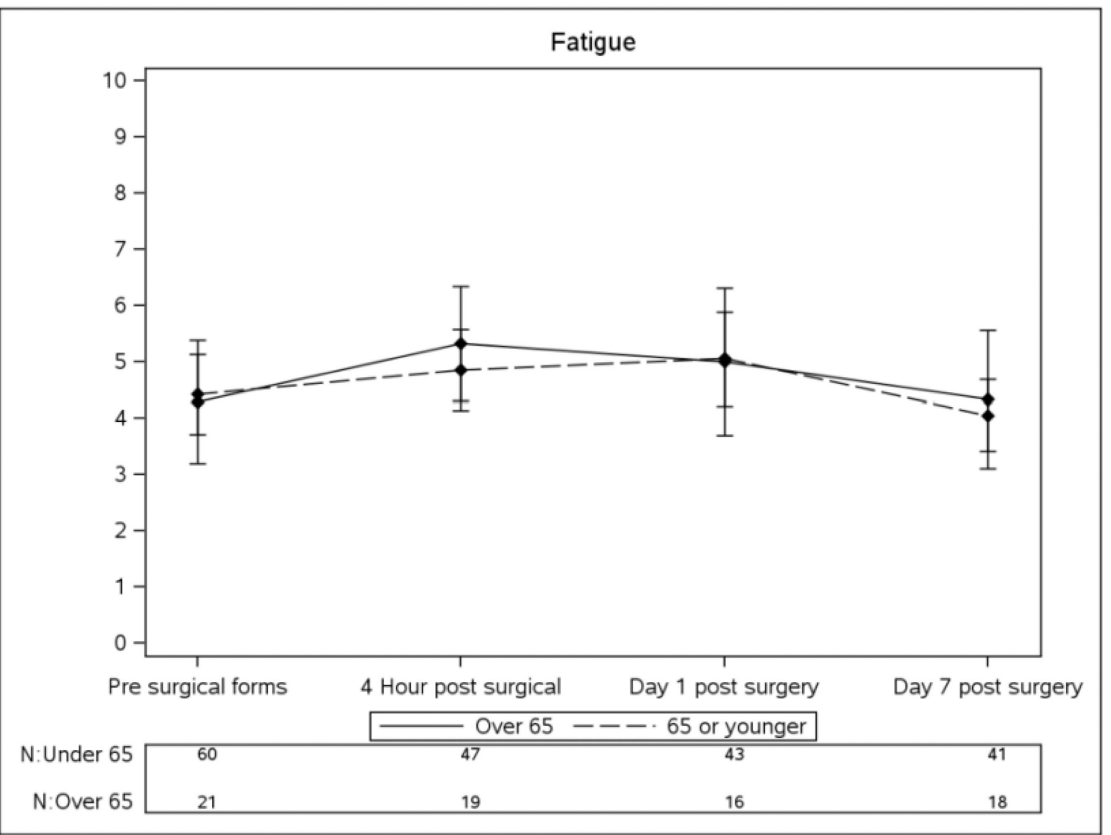

Figure 5.

Fatigue as a measure by LASA over time: a) by procedure type, $\mathrm{N}$ denotes the number of available data points from patients undergoing basic or advanced laparoscopic procedures included at each time point in the analysis b) by age group, $\mathrm{N}$ denotes the number of available data points from patients older or younger than 65 included at each time point in the analysis 


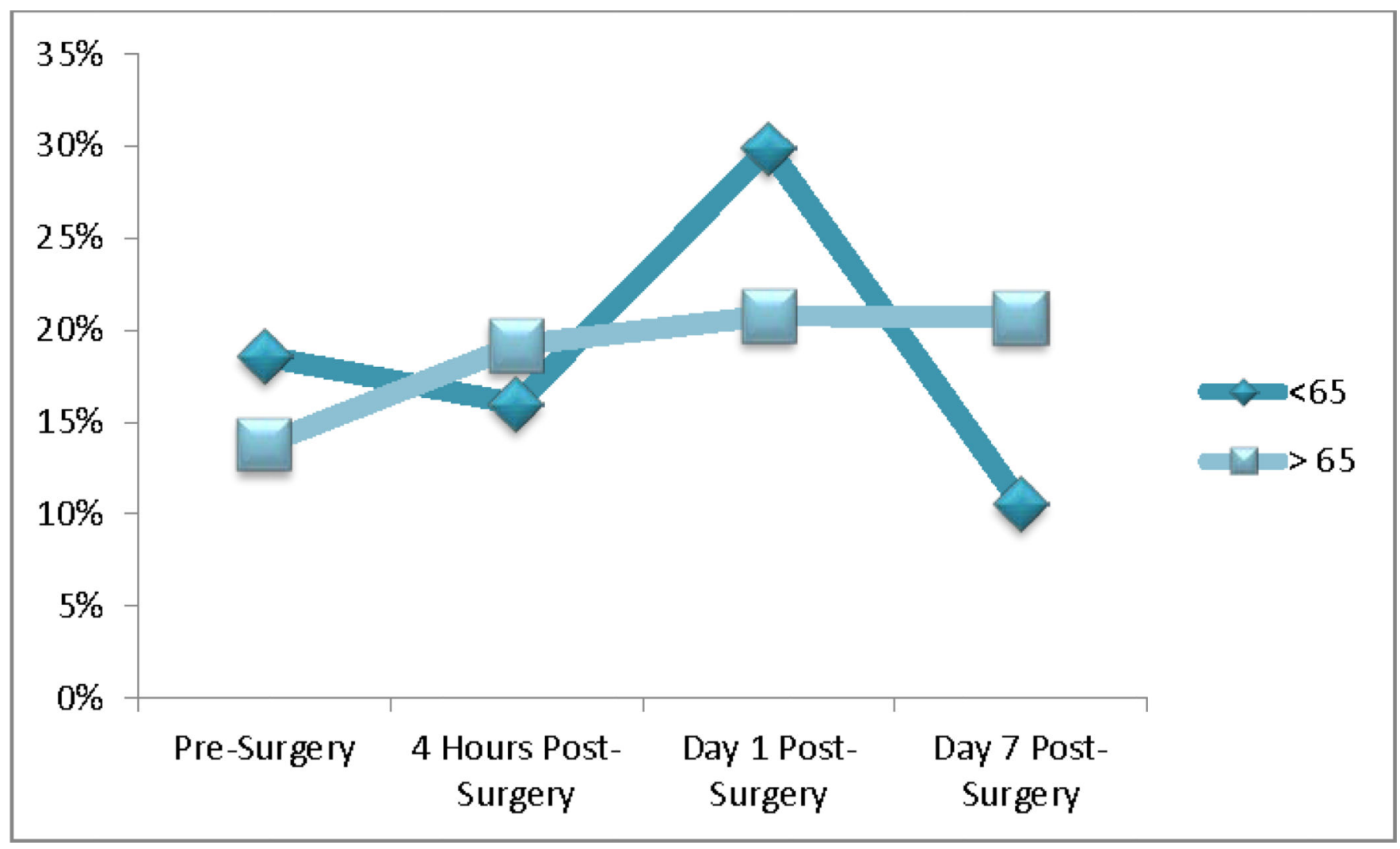

Figure 6.

Percentage of patients with clinically significant QOL deficit (LASA score $<5 / 10$ ) in the perioperative time for patients older $(n=29)$ or younger $(n=83)$ than 65 years old 


\section{Table 1}

Baseline PROMIS and VAS scores

\begin{tabular}{|c|c|c|c|c|}
\hline \multicolumn{5}{|c|}{ Baseline PROMIS ${ }^{a}$ and VAS $^{b}$ Scores by Gender } \\
\hline & $\begin{array}{l}\text { Female } \\
(\mathrm{N}=67)\end{array}$ & $\begin{array}{c}\text { Male } \\
(\mathrm{N}=48)\end{array}$ & $\begin{array}{c}\text { Total } \\
(\mathbf{N}=115)\end{array}$ & p value \\
\hline Physical T-Score & & & & $0.1887^{1}$ \\
\hline $\mathrm{N}$ & 64 & 43 & 107 & \\
\hline Mean (SD) & $46.7(8.8)$ & $48.5(7.6)$ & $47.4(8.3)$ & \\
\hline Median & 47.7 & 50.8 & 47.7 & \\
\hline Q1, Q3 & $39.8,54.1$ & $44.9,54.1$ & $42.3,54.1$ & \\
\hline Range & $(29.6-67.7)$ & $(26.7-61.9)$ & $(26.7-67.7)$ & \\
\hline Mental T-Score & & & & $0.1920^{1}$ \\
\hline $\mathrm{N}$ & 63 & 45 & 108 & \\
\hline Mean (SD) & $48.7(7.6)$ & $50.7(7.7)$ & $49.5(7.7)$ & \\
\hline Median & 48.3 & 53.3 & 50.8 & \\
\hline Q1, Q3 & $43.5,53.3$ & $45.8,53.3$ & $45.8,53.3$ & \\
\hline Range & $(28.4-62.5)$ & $(33.8-67.6)$ & $(28.4-67.6)$ & \\
\hline EQ5D Score & & & & $0.1859^{1}$ \\
\hline $\mathrm{N}$ & 62 & 43 & 105 & \\
\hline Mean (SD) & $0.7(0.1)$ & $0.7(0.1)$ & $0.7(0.1)$ & \\
\hline Median & 0.7 & 0.7 & 0.7 & \\
\hline Q1, Q3 & $0.6,0.8$ & $0.7,0.8$ & $0.6,0.8$ & \\
\hline Range & $(0.5-0.9)$ & $(0.4-0.8)$ & $(0.4-0.9)$ & \\
\hline Pain Level & & & & $0.3173^{1}$ \\
\hline $\mathrm{N}$ & 65 & 45 & 110 & \\
\hline Mean (SD) & $1.7(2.5)$ & $1.8(2.1)$ & $1.7(2.3)$ & \\
\hline Median & 0.5 & 1.0 & 0.6 & \\
\hline Q1, Q3 & $0.0,3.0$ & $0.0,2.3$ & $0.0,3.0$ & \\
\hline Range & $(0.0-9.0)$ & $(0.0-8.5)$ & $(0.0-9.0)$ & \\
\hline Kruskal Wallis & & & & \\
\hline
\end{tabular}




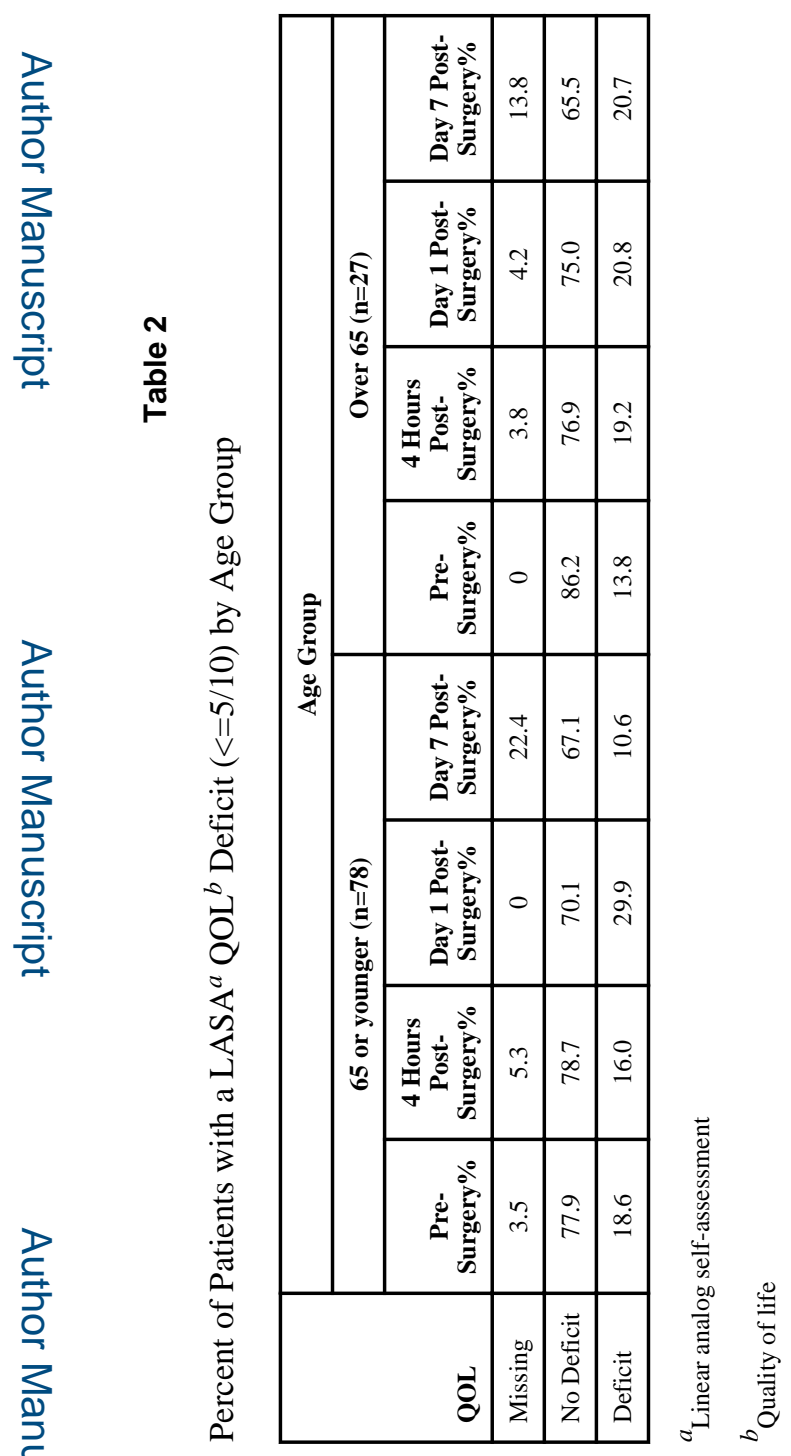




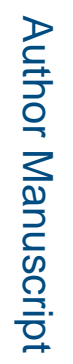

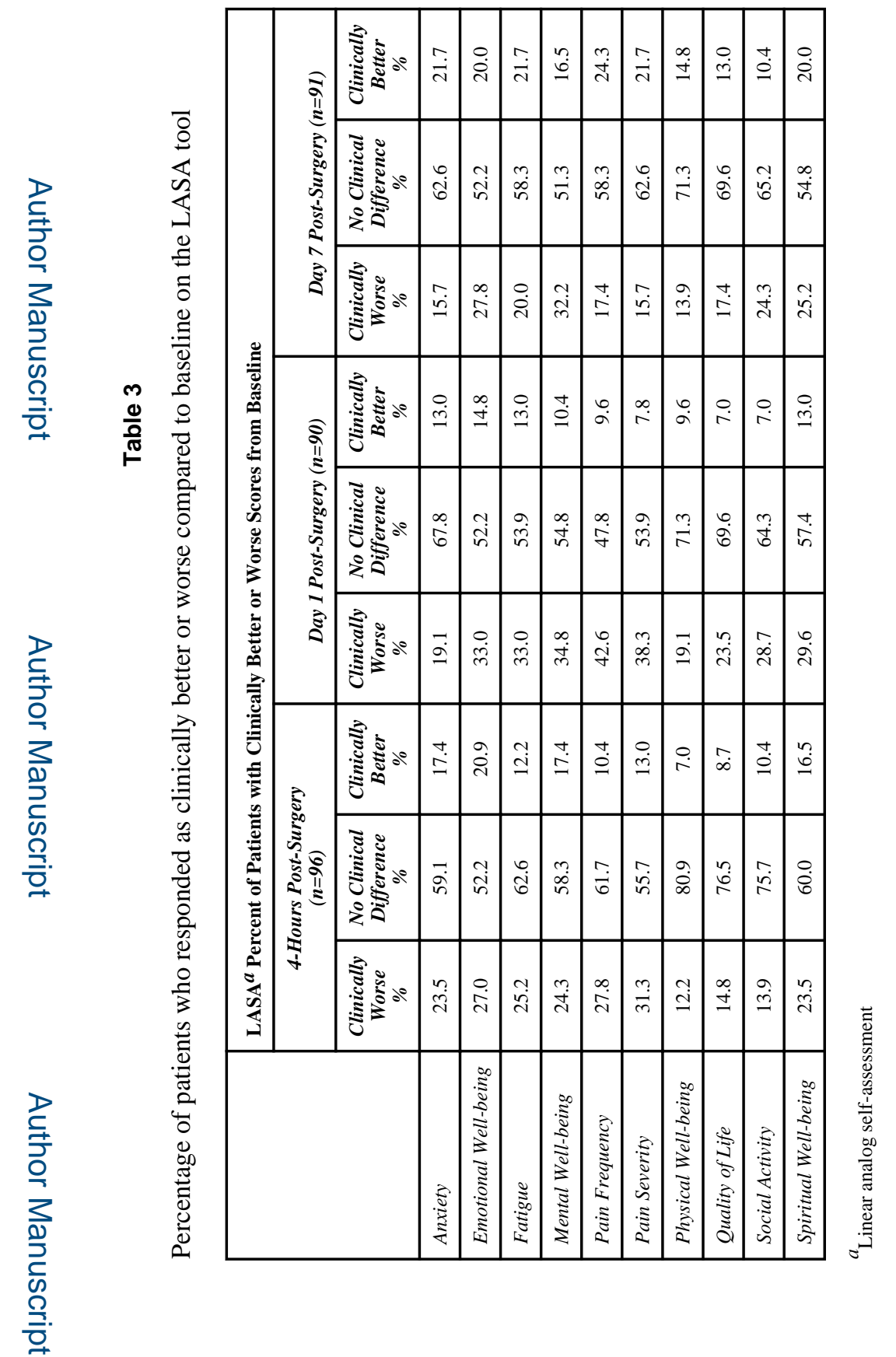

J Gastrointest Surg. Author manuscript; available in PMC 2016 May 01. 
Table 4

Comparison of PROMIS and LASA data on change within subject

\begin{tabular}{|l|c|c|c|c|}
\hline & $\begin{array}{c}\text { PROMIS }^{\boldsymbol{a}} \text {-10 } \\
\text { Individuals (\%) } \\
\text { worse } \\
\text { Postoperative } \\
\text { day 1 } \\
\text { (T-scores, fatigue } \\
\text { individual item) } \\
\text { (n=90) }\end{array}$ & $\begin{array}{c}\text { PROMIS-10 } \\
\text { Individuals (\%) } \\
\text { worse } \\
\text { Postoperative } \\
\text { day 7 } \\
\text { (EQ5D, T-scores, } \\
\text { fatigue individual } \\
\text { item) (n=91) }\end{array}$ & $\begin{array}{c}\text { LASA } \boldsymbol{b} \\
\text { Individuals (\%) } \\
\text { worse } \\
\text { Postoperative } \\
\text { day 1 (n=90) }\end{array}$ & $\begin{array}{c}\text { LASA } \\
\text { Individuals (\%) } \\
\text { worse } \\
\text { Postoperative } \\
\text { day 7 (n=91) }\end{array}$ \\
\hline Overall well-being & 38 & 24 & 24 & 17 \\
\hline Physical well-being & 40 & 25 & 19 & 14 \\
\hline Mental well-being & 18 & 11 & 35 & 32 \\
\hline Fatigue & 31 & 23 & 33 & 20 \\
\hline Pain frequency & -- & -- & 43 & 17 \\
\hline
\end{tabular}

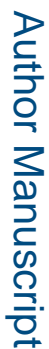

${ }^{a}$ Patient-reported outcomes measures information system

${ }^{b}$ Linear analog self-assessment 